\title{
A solid-state chemist's eye for the development of materials science in China
}

\author{
Yadong Li
}

\section{PREFACE}

Chemistry, especially solid-state chemistry, always plays an important role in materials science with respect to the discovery of new compounds and structure-property correlations. Professor Kenneth R. Poeppelmeier is an internationally renowned, intellectual leader in the research for synthesis and structure of new materials, and their technologically important properties. Turning 70 this year and still immersed in solid-state chemistry, he continues to make special contributions to the development of materials science in China. In celebration of his 70th birthday, this editorial summarizes Professor Poeppelmeier's many connections with Chinese professors and students and lists his contributions to the discovery of acentric materials, oxide-based catalysts, luminescent materials, and transparent conducting oxides. Important design principles leading to new materials have been proposed with his Chinese collaborators, which demonstrate successful routes to materials and performance optimization.

Professor Kenneth R. Poeppelmeier was born in 1949 in Missouri, USA, and received his $\mathrm{BSc}$ and $\mathrm{PhD}$ from the University of Missouri and Iowa State University, respectively. He is now a Charles E. \& Emma H. Morrison Professor of Chemistry in the Department of Chemistry at Northwestern University. During his forty-year research career, he has fused a deep understanding of inorganic chemistry with sharp insights into the connection between structure and function, producing a unique and elegant body of work that has defined modern solid-state chemistry, in which some conceptual approaches have been also epitomized to guide the discovery of noncentrosymmetric crystals, transparent conducting oxides, and rare earth luminescent materials, etc. Professor Poeppelmeier is a tremendously engaging and effective lecturer with infectious enthusiasm for chemistry that is readily appreciated by a variety of audiences.

\section{VISITING CHINA AND LEADING RESEARCH FROM SOLID-STATE CHEMISTRY TO MATERIALS SCIENCE}

Professor Poeppelmeier made his first connection with China when he visited several universities in Taiwan in 1991. He subsequently arrived in Beijing in 1997 to attend the $\mathrm{M}^{2} \mathrm{~S}-1997$ High-Temperature Superconductivity meeting, which was his first trip to the mainland of China. These visits sparked a deep connection between Professor Poeppelmeier and the solid-state chemists in China, marking the beginning of a profound friendship. In 1997, Professor Yadong Li hosted Professor Poeppelmeier for the latter's visit to the University of Science and Technology of China in Hefei as well as to Peking University and Tsinghua University in Beijing, where Professor Poeppelmeier met several Chinese solid-state chemists including Professor Chuangtian Chen. In 2004, Professor Poeppelmeier visited Jilin University for Chemistry Week in China, hosted by Professor Shouhua Feng. In 2005, Professor Poeppelmeier attended the Solid State and Inorganic Chemistry meeting in Beijing, meeting many more Chinese solid-state and inorganic chemists. By this time, Dr. Shilie Pan had joined Professor Poeppelmeier's group as a postdoctoral researcher and published joint papers from 2004 to 2014 on acentric materials for nonlinear optics applications. After a nineyear break, Professor Poeppelmeier made another long trip to China in 2014, visiting Beijing, Urumqi, Xi'an, Fuzhou, and Shanghai, where he met many old friends and made some new ones. His visits then became more frequent as he traveled to China in 2016, 2018, and 2019 for various conferences, including the Chinese Solid State 
and Inorganic Chemistry Meeting, International Symposium on Rare Earth Resource Utilization, and Nature Conference on Emergent Materials and Devices, respectively. Fig. 1 shows photos of Professor Poeppelmeier as a plenary speaker at the Nature Conference held in Chengdu (a) and with Professor Yadong Li (b).

\section{CONTRIBUTING TO NEW MATERIALS DISCOVERY AND ESTABLISHING DESIGN PRINCIPLES}

\section{Breaking the inversion symmetry to design new acentric materials}

Professor Poeppelmeier's work on acentric materials illustrates his ability to open up new directions of both basic and technological importance through creative chemical thinking. Although acentric materials (such as lead zirconate titanate used in actuators and barium borate used in nonlinear optical applications) are key to current technologies, there is no unified chemical understanding of how they arise, frustrating those who attempt to design them. Prior to Professor Poeppelmeier's work, such materials were often discovered largely by accident, and no common understanding informed their design.

Professor Poeppelmeier's research focuses on one central question: why are acentric materials such a small subset of crystalline materials when the majority of possible space groups are noncentrosymmetric? His insights into this fundamental issue have begun to unify and generalize the rational synthesis of acentric materials. This work began with a review article with Professor Halasyamani (Fig. 2) that started a renaissance in this field [1]. By examining all the known acentric oxides and connecting their chemistry to their structures, they developed design rules for synthesizing new acentric materials. This new approach not only led Professor
Poeppelmeier to discover entirely new routes to new acentric materials [2] but also influenced huge numbers of other groups working in this area $[3,4]$.

Recently, Professor Poeppelmeier and co-workers [5] made the profound observation that optical activity, i.e., circular dichroism, should be possible in racemic, achiral noncentrosymmetric compounds. This observation overturned a long-held assumption that chirality was required for optical activity. This same fundamental understanding of how nonlinear optical activity is controlled by chemistry drove an imaginative synthetic program that led to new families of high-performing nonlinear optical systems, e.g., $\mathrm{LiCs}_{2} \mathrm{PO}_{4}$ [6] with 2.6 times the response of the benchmark $\mathrm{KH}_{2} \mathrm{PO}_{4}(\mathrm{KDP})$ and a new deep-ultraviolet nonlinear optical material, $\mathrm{NH}_{4} \mathrm{~B}_{4} \mathrm{O}_{6} \mathrm{~F}$ [7], capable of replacing Be-containing $\mathrm{KBe}_{2} \mathrm{BO}_{3} \mathrm{~F}_{2}$. This work translated the basic chemical understanding into new materials of interest to device developers. Beryllium-free $\mathrm{NH}_{4} \mathrm{~B}_{4} \mathrm{O}_{6} \mathrm{~F}$ (Fig. 3) not only inherited the favorable structural characteristics of $\mathrm{KBe}_{2} \mathrm{BO}_{3} \mathrm{~F}_{2}$ but also possessed balanced optical properties. Thus, $\mathrm{NH}_{4} \mathrm{~B}_{4} \mathrm{O}_{6} \mathrm{~F}$ became the most likely candidate for generating a deep-UV laser by the direct second harmonic generation method.

\section{Searching for heterogeneous catalysts and new oxide optical materials}

Professor Poeppelmeier's chemical understanding of the solid state is exceptional, demonstrated by his seminal work connecting defect ordering to metal coordination geometry in oxidation catalysts at Exxon Research and Development [8-10]. An impactful and profound review on double perovskites [11] that determined three specific cation arrangements was also published by his group. Importantly, he explained that a specific sublattice arrangement had implications for cuprate superconductors. This was followed by the aptly titled publication, 'Discovering New Oxides' [12], in which he explained the
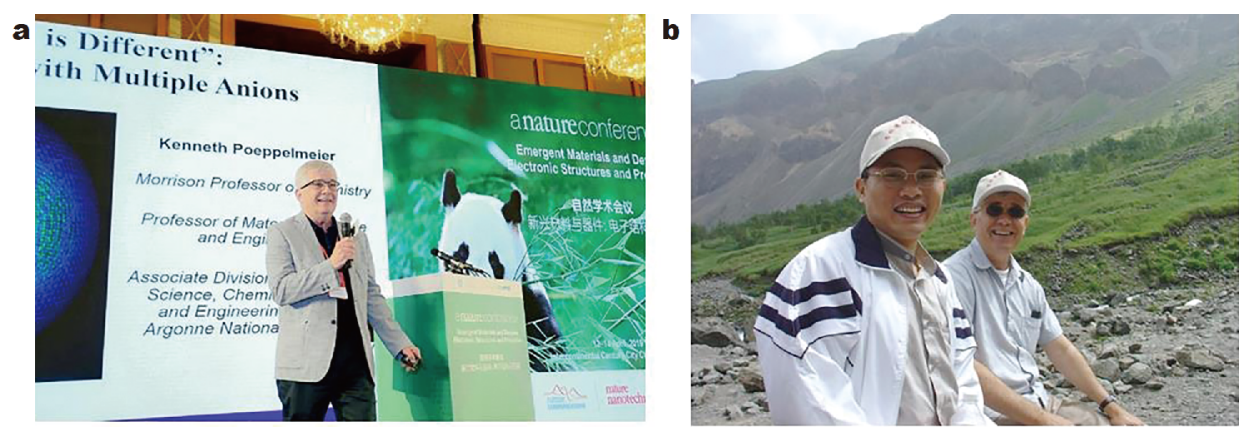

Figure 1 (a) Professor Kenneth R. Poeppelmeier as a plenary speaker at the Nature Conference held in Chengdu. (b) Professor Kenneth R. Poeppelmeier in China with Professor Yadong Li. 


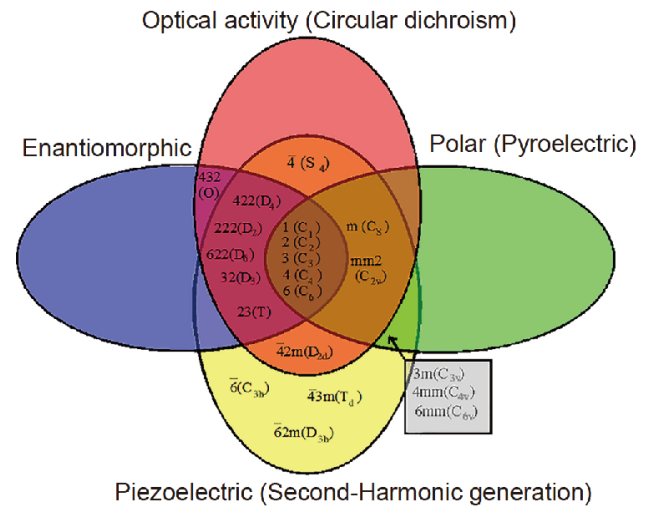

Figure 2 Interrelationships of noncentrosymmetric crystal classes using both Hermann-Mauguin and Schoenflies symbols. Adapted with permission from Ref. [1], Copyright 1998, American Chemical Society.

umbrella concept for the formation of unconventional structures in multi-cation systems. He further identified chemically sensible structures for complex oxide surfaces $[13,14]$.

Professor Poeppelmeier's research has had tremendous implications for understanding thin film growth on oxide substrates and has more recently led to identification of the surface structures of oxide nanoparticles [15]. This harnessing of chemistry to address key fundamental and applied issues is typical; for example, the success of his collaboration with Northwestern colleagues on identify- ing new transparent conducting oxides (TCOs) is further testament to this (Fig. 4) [16-18]. Professor Poeppelmeier's TCO work spans multiple disciplines but is driven by a clear understanding of solid-state inorganic materials chemistry. The impact of this approach is shown in the highly cited overview in MRS Bulletin [19].

Professor Poeppelmeier has made many other important contributions, from his recent work on new highly stable solid oxide fuel cell anodes and Mg battery electrodes to his studies of cation ordering in oxides, including high-temperature superconductors. Professor Poeppelmeier's thorough understanding of the chemical control of physical phenomena in extended solids is exemplified by two new exciting research directions: nanoscale control of photoluminescence by local cation segregation [20] and reconstructive transitions triggered by complex anion reorientation (Fig. 5) [21]. Both these publications are typical of the fresh insights that continually emerge from his laboratory.

\section{Building materials design principles and collaboration with computational researchers}

Professor Poeppelmeier's extensive career has focused on establishing structural design principles and continues to take new directions. The idea of chemical unit cosubstitution is explored as a useful "pairing" concept that can potentially lead to the creation of many new members of
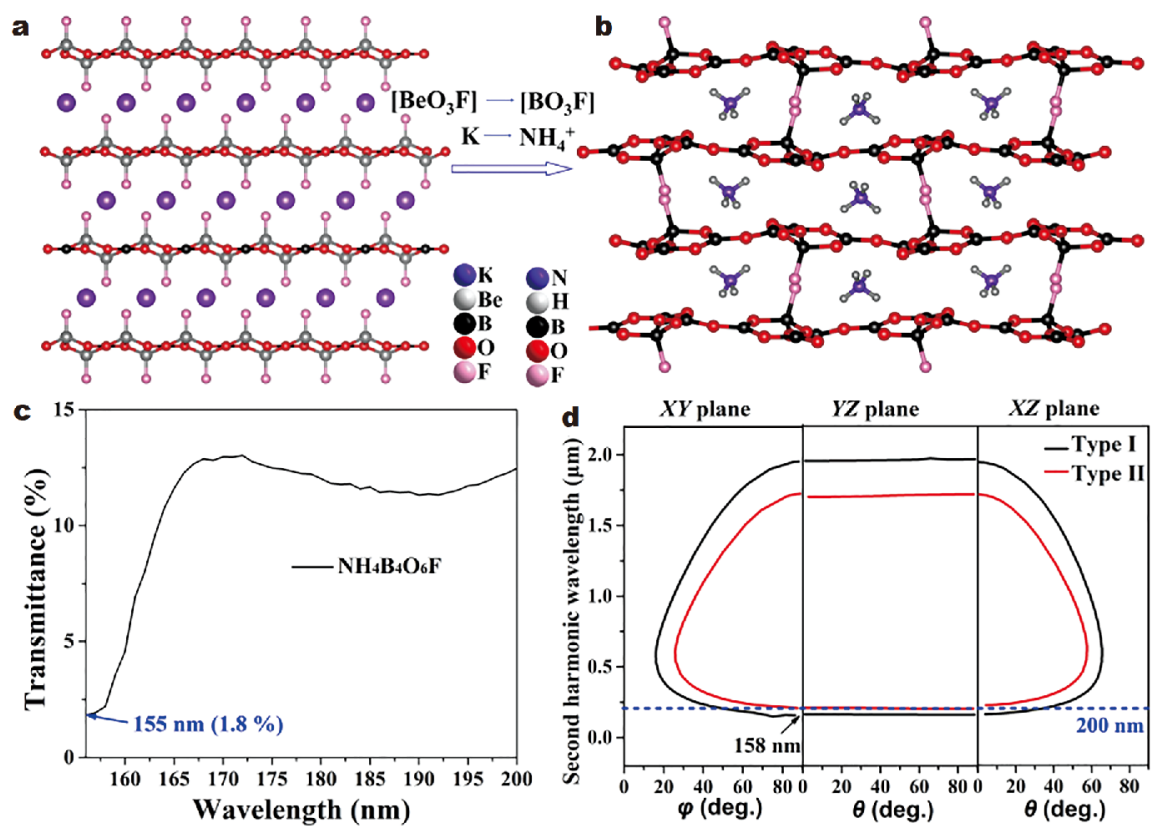

Figure 3 Structural evolution from $\mathrm{KBBF}$ to $\mathrm{NH}_{4} \mathrm{~B}_{4} \mathrm{O}_{6} \mathrm{~F}(\mathrm{a}, \mathrm{b})$, transmission spectra (c) and phase-matching conditions (d) for $\mathrm{NH}_{4} \mathrm{~B}_{4} \mathrm{O}_{6} \mathrm{~F}$ crystal. Adapted with permission from Ref. [7], Copyright 2017, American Chemical Society. 


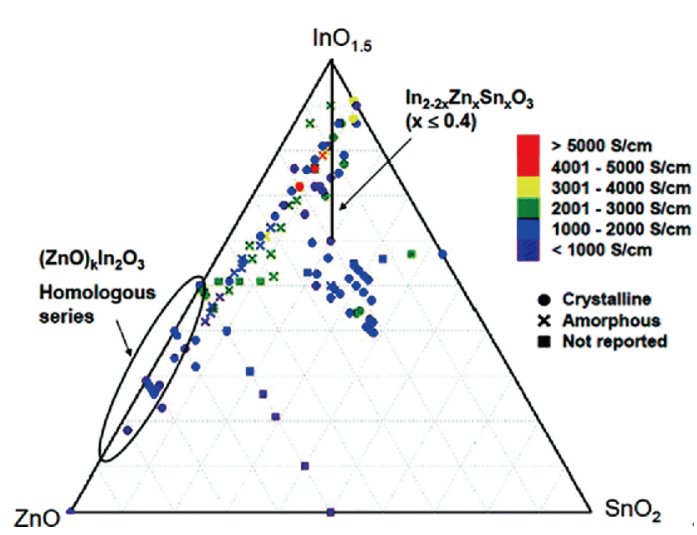

Figure 4 Reported ZITO films plotted by composition. Films denoted by a circle contain at least one crystalline phase. Adapted with permission from Ref. [16], Copyright 2010, American Chemical Society.

a particular framework structure. Cosubstitution is defined as the simultaneous replacement of two or more cations, anions, complex anions, other fundamental building units, or vacancies. Although the overall sum of the oxidation states remains constant, individual components are not necessarily isovalent. Such a strategy can be readily applied to extend and modify the properties of solid-state compounds, including nonlinear optical materials, luminescent materials, TCOs, and photocatalytic and photovoltaic materials [22,23]. Recently, another design principle toward the discovery of a blue-light-excited $\mathrm{Eu}^{2+}$-doped red-emitting oxide-based phosphor was proposed based on the collaborative work of Professor Kenneth R. Poeppelmeier and Professor Zhiguo Xia, which was applied to screening of activator site occupation in polyhedra with small coordination numbers $(\mathrm{CNs})$; accordingly, $\mathrm{Eu}^{2+}$ ions were located at $\mathrm{Rb}^{2+}$ and $\mathrm{Y}^{3+}$ cation sites of $\mathrm{Rb}_{3} \mathrm{YSi}_{2} \mathrm{O}_{7}$ with $\mathrm{CN}=6$, and a new oxide-based phosphor, $\mathrm{Rb}_{3} \mathrm{YSi}_{2} \mathrm{O}_{7}$ :Eu was discovered that demonstrated a broadband red emission under $450 \mathrm{~nm}$ blue light excitation [24].

Professor Poeppelmeier has also driven collaborative work with computational researchers to develop and perform material property calculations to discover novel materials with designed target functionality [25]. This pioneering work fused his understanding of the crystal chemistry that opened up new material classes with the power of modern computational methods, allowing the discovery of hitherto unknown compounds in the laboratory. The success of this approach demonstrated to the research community that chemical understanding, rather than brute-force screening, is the ideal route to effective use of computation in materials discovery. Re-

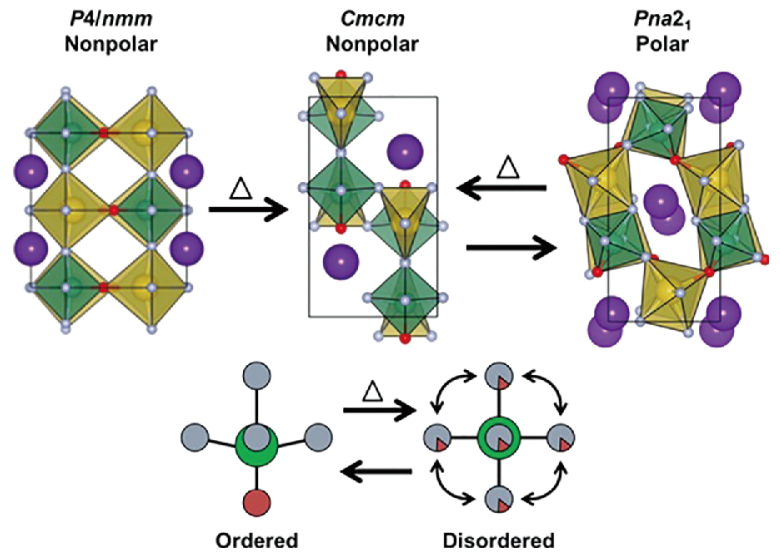

Figure 5 Sketch of reconstructive transitions triggered by complex anion reorientation. Adapted with permission from Ref. [21], Copyright 2016, American Chemical Society.

cently, Professor Poeppelmeier was also Editor-in-Chief with Jan Reedijk of the nine-volume reference series, Comprehensive Inorganic Chemistry, 2nd Edition. This much needed work followed the classic 1973 1st Edition edited by Bailar, Emeléus, Nyholm, and Trotman-Dickenson. Professor Poeppelmeier led the effort and coordinated contributions from hundreds of experts from around the world. The articles were written at a level that provided undergraduate students and active researchers with a ready reference resource in the field of inorganic chemistry. This daunting task was, by every measure, a great success.

This series of research results led by Professor Poeppelmeier is encouraging and can guide chemists with new thoughts in the fields of acentric materials, oxide-based catalysis, luminescent materials, and TCOs. More importantly, the in-depth collaboration between Professor Poeppelmeier and Chinese chemists has led both sides to make better breakthroughs in solid-state chemistry and related fields.

\section{Received 19 September 2019; accepted 23 September 2019;} published online 26 September 2019

1 Halasyamani PS, Poeppelmeier KR. Noncentrosymmetric oxides. Chem Mater, 1998, 10: 2753-2769

2 Marvel MR, Lesage J, Baek J, et al. Cation-anion interactions and polar structures in the solid state. J Am Chem Soc, 2007, 129: 13963-13969

3 Chen MC, Wu LM, Lin $\mathrm{H}$, et al. Disconnection enhances the second harmonic generation response: synthesis and characterization of $\mathrm{Ba}_{23} \mathrm{Ga}_{8} \mathrm{Sb}_{2} \mathrm{~S}_{38}$. J Am Chem Soc, 2012, 134: 6058-6060

4 Rondinelli JM, May SJ, Freeland JW. Control of octahedral connectivity in perovskite oxide heterostructures: An emerging route to multifunctional materials discovery. MRS Bull, 2012, 37: 261- 
270

5 Gautier R, Klingsporn JM, Van Duyne RP, et al. Optical activity from racemates. Nat Mater, 2016, 15: 591-592

6 Li L, Wang Y, Lei BH, et al. A new deep-ultraviolet transparent orthophosphate $\mathrm{LiCs}_{2} \mathrm{PO}_{4}$ with large second harmonic generation response. J Am Chem Soc, 2016, 138: 9101-9104

7 Shi G, Wang Y, Zhang F, et al. Finding the next deep-ultraviolet nonlinear optical material: $\mathrm{NH}_{4} \mathrm{~B}_{4} \mathrm{O}_{6}$ F. J Am Chem Soc, 2017, 139: 10645-10648

8 Poeppelmeier KR, Leonowicz ME, Longo JM. $\mathrm{CaMnO}_{2.5}$ and $\mathrm{Ca}_{2} \mathrm{MnO}_{3.5}$ : New oxygen-defect perovskite-type oxides. J Solid State Chem, 1982, 44: 89-98

9 Poeppelmeier KR, Leonowicz ME, Scanlon JC, et al. Structure determination of $\mathrm{CaMnO}_{3}$ and $\mathrm{CaMnO}_{2.5}$ by X-ray and neutron methods. J Solid State Chem, 1982, 45: 71-79

10 Poeppelmeier KR, Longo JM. Oxygen Deficient Manganese Perovskites. US Patent 4388294, 1983

11 Anderson M, Greenwood K, Taylor G, et al. B-cation arrangements in double perovskites. Prog Solid State Chem, 1993, 22: 197-233

12 Vander Griend DA, Malo S, Wang TK, et al. Discovering new oxides. J Am Chem Soc, 2000, 122: 7308-7311

13 Erdman N, Poeppelmeier KR, Asta M, et al. The structure and chemistry of the $\mathrm{TiO}_{2}$-rich surface of $\mathrm{SrTiO}_{3}$ (001). Nature, 2002, 419: $55-58$

14 Enterkin JA, Subramanian AK, Russell BC, et al. A homologous series of structures on the surface of $\mathrm{SrTiO}_{3}(110)$. Nat Mater, 2010, 9: 245-248

15 Lin $\mathrm{Y}, \mathrm{Wu} \mathrm{Z}$, Wen J, et al. Imaging the atomic surface structures of $\mathrm{CeO}_{2}$ nanoparticles. Nano Lett, 2014, 14: 191-196
16 Hoel CA, Mason TO, Gaillard JF, et al. Transparent conducting oxides in the $\mathrm{ZnO}-\mathrm{In}_{2} \mathrm{O}_{3}-\mathrm{SnO}_{2}$ system. Chem Mater, 2010, 22: 3569-3579

17 Palmer GB, Poeppelmeier KR, Mason TO. Conductivity and transparency of $\mathrm{ZnO} / \mathrm{SnO}_{2}$-cosubstituted $\mathrm{In}_{2} \mathrm{O}_{3}$. Chem Mater, 1997, 9: 3121-3126

18 Edwards DD, Mason TO, Goutenoire F, et al. A new transparent conducting oxide in the $\mathrm{Ga}_{2} \mathrm{O}_{3}-\mathrm{In}_{2} \mathrm{O}_{3}-\mathrm{SnO}_{2}$ system. Appl Phys Lett, 1997, 70: 1706-1708

19 Freeman AJ, Poeppelmeier KR, Mason TO, et al. Chemical and thin-film strategies for new transparent conducting oxides. MRS Bull, 2000, 25: 45-51

20 Xia Z, Liu G, Wen J, et al. Tuning of photoluminescence by cation nanosegregation in the $(\mathrm{CaMg})_{x}(\mathrm{NaSc})_{1-x} \mathrm{Si}_{2} \mathrm{O}_{6}$ solid solution. J Am Chem Soc, 2016, 138: 1158-1161

21 Holland M, Charles N, Rondinelli JM, et al. Reconstructive transitions from rotations of rigid heteroanionic polyhedra. J Am Chem Soc, 2016, 138: 11882-11889

22 Xia Z, Ma C, Molokeev MS, et al. Chemical unit cosubstitution and tuning of photoluminescence in the $\mathrm{Ca}_{2}\left(\mathrm{Al}_{1-x} \mathrm{Mg}_{x}\right)\left(\mathrm{Al}_{1-x} \mathrm{Si}_{1+x}\right) \mathrm{O}_{7}$ : $\mathrm{Eu}^{2+}$ phosphor. J Am Chem Soc, 2015, 137: 12494-12497

23 Xia Z, Poeppelmeier KR. Chemistry-inspired adaptable framework structures. Acc Chem Res, 2017, 50: 1222-1230

24 Qiao J, Ning L, Molokeev MS, et al. Site-selective occupancy of $\mathrm{Eu}^{2+}$ toward blue-light-excited red emission in a $\mathrm{Rb}_{3} \mathrm{YSi}_{2} \mathrm{O}_{7}: \mathrm{Eu}$ phosphor. Angew Chem Int Ed, 2019, 58: 11521-11526

25 Gautier R, Zhang X, Hu L, et al. Prediction and accelerated laboratory discovery of previously unknown 18-electron ABX compounds. Nat Chem, 2015, 7: 308-316 